\title{
Proposta de índice de Qualidade para Água Bruta afluente a estações convencionais de tratamento
}

\section{Proposal of a raw water quality index influent to conventional water treatment plants}

\author{
Maria Eugênia Tavares Abreu de Souza \\ Engenheira Civil. Mestre em Saneamento, Meio Ambiente e Recursos Hídricos pela Universidade Federal de Minas Gerais (UFMG)
}

\section{Marcelo Libânio}

Engenheiro Civil. Mestre em Engenharia Sanitária pela UFMG. Doutor em Hidráulica e Saneamento pela Universidade de São Paulo (USP). Pós-doutorado pela Universidade de Alberta (Canadá). Pesquisador do Conselho Nacional de Desenvolvimento Científico e Tecnológico (CNPq) e da Fundação de Amparo à

Pesquisa do Estado de Minas Gerais (Fapemig). Professor-associado do Departamento de Engenharia Hidráulica e Recursos Hídricos da UFMG

\section{Resumo}

O presente trabalho tem por objetivo propor um Índice de Qualidade da Água Bruta (IQAB) afluente para estações convencionais de tratamento que permita comparar a tratabilidade dos mananciais superficiais. A metodologia Delphi para a elaboração do IQAB fundamentou-se basicamente na mesma utilizada para o desenvolvimento do Índice de Qualidade de Água, no início da década de 1970, contando com um painel composto inicialmente por 24 especialistas De acordo com a opinião do painel, o IQAB foi composto por oito parâmetros comumente monitorados em parcela significativa das estações brasileiras Sua aplicação a cinco mananciais superficiais permite recomendar seu emprego como ferramenta adicional de avaliação da performance das estações de tratamento pelas concessionárias de abastecimento de água do país.

Palavras-chave: qualidade de água; índice de qualidade de água; tratamento de água.

\section{Abstract}

This paper has the objective of proposing a Raw Water Quality Index (RWQI) influent for the conventional water treatment plants that allow the comparison of the treatability of distinct surface water sources. The Delphi methodology was employed similarly to that employed for the development of Water Quality Index, in the beginning of the 1970's, with a panel composed by 24 specialists. According to the panel opinion, the RWQI was composed by eight water quality parameters usually monitored in a significant portion of Brazilian plants. Its application on five surface water sources allows the recommendation of its use as an additional tool for the assessment of the performance of water treatment plants operated by the Brazilian sanitation companies.

Keywords: water quality; water quality index; water treatment.

\section{Introdução}

A avaliação da performance das estações de tratamento realizada pelas concessionárias de abastecimento de água no País comumente norteia-se pela qualidade do efluente tratado ou, em outras palavras, pelo percentual do tempo de operação da unidade durante o qual o efluente atendeu às premissas estabelecidas pela Portaria 518 (BRASIL, 2004). Tais premissas reportam-se a um rol de 72 parâmetros de qualidade da água para consumo humano, classificados como: de aceitação (18), orgânicos (13) e inorgânicos (13); e às concentrações máximas permissíveis de 23 agrotóxicos e 6 subprodutos da desinfecção com compostos de cloro.

A despeito de quão usual este procedimento tem se tornado, uma análise mais abrangente do desempenho das estações de tratamento de água teria de contemplar: i) as características físicas, químicas e biológicas do afluente e sua adequabilidade à tecnologia de tratamento;

ii) o índice de sobrecarga da estação de tratamento expresso pela relação entre a vazão média afluente e as dimensões das unidades responsáveis pelos processos e operações unitárias inerentes à potabilização;

iii) a intangível acurácia da operação.

Embora seja intrinsecamente difícil estabelecer hierarquias absolutas em tratamento de água, o desenvolvimento de ferramentas que permitam avaliar a tratabilidade da água bruta e a capacidade da estação fará com que se evidencie a qualidade da operação.

No que tange especificamente ao tratamento, foi dado um primeiro passo nesta direção com o desenvolvimento do Índice de Qualidade de Estações de Tratamento de Água (IQETA), contemplando 
19 parâmetros, a quase totalidade (17) constituída de parâmetros hidráulicos relacionando a vazão afluente às características físicas da instalação potabilizadora. Desta forma, a partir da vazão afluente e das características físicas da estação, atribui-se, por meio de um produtório, uma nota entre 0 e 100 (LIBÂNIO; LOPES, 2009).

Em conjunto com o IQETA, o desenvolvimento de um índice que possa aferir a tratabilidade das águas naturais tornará a avaliação do desempenho das estações ainda mais preciso. Em outras palavras, o fato de determinada estação de tratamento com elevado IQETA, e à qual aflui água bruta de fácil tratabilidade, apresentar efluente de má qualidade - em termos da turbidez do filtrado - constitui um forte indicativo de operação insatisfatória. Em contrapartida, estação de tratamento operando com sobrecarga, e consequentemente com baixo IQETA, à qual aflui água natural de difícil tratabilidade e apresentando elevada qualidade do filtrado, certamente há de apresentar operação adequada.

Esta perspectiva torna-se ainda mais útil às companhias estaduais de saneamento, pois permitirá identificar com maior exatidão as unidades com baixo desempenho e alocar melhor os recursos para ampliação e/ou treinamento de pessoal. Ilustra esta assertiva o fato de a Companhia de Saneamento de Minas Gerais (Copasa) responder pela operação de 645 estações de tratamento no Estado, sendo que quase a totalidade emprega tecnologia convencional de potabilização.

\section{Objetivos}

Diante do exposto, o objetivo geral do trabalho consiste em propor um Índice de Qualidade de Água Bruta (IQAB) aplicável ao afluente a estações convencionais de tratamento.

Em segunda instância, o trabalho visa:

i) hierarquizar as características físicas, químicas e biológicas das águas superficiais em função da tratabilidade por meio da tecnologia convencional de potabilização;

ii) desenvolver os critérios de pontuação para os oito principais parâmetros inseridos no IQAB;

iii) aplicar o índice recém-desenvolvido a cinco águas naturais afluentes a estações de tratamento de médio e grande porte.

\section{Revisão da literatura}

\section{A metodologia Delphi}

A metodologia Delphi constitui uma ferramenta para obtenção de consenso acerca de temas polêmicos calcada na opinião de um grupo de especialistas. Para atingir este objetivo, quatro características devem permear a sua aplicação (LINSTONE; TUROFF, 1975):

(i) a garantia do anonimato, visando a reduzir fatores psicológicos, tais como a possível influência da opinião de participantes com maior grau de especialização sobre os demais; (ii) a interação por meio das várias rodadas de questionários, permitindo aos participantes revisarem suas decisões;

(iii) o feedback, controlado entre duas rodadas de questionários para informar cada membro do grupo da opinião dos demais, comumente apresentado como um sumário numérico anexado aos argumentos apresentados pelos painelistas;

(iv) a representação estatística dos resultados.

Geralmente, o questionário é bastante detalhado, apresentando para cada questão uma síntese das principais informações conhecidas sobre o assunto e, eventualmente, extrapolações para o futuro. As respostas das questões quantitativas são tabuladas por meio de tratamento estatístico simples, definindo-se a mediana, os quartis e os resultados remetidos aos participantes na segunda rodada. A cada roda$\mathrm{da}$, as perguntas eram repetidas e os participantes deveriam reavaliar suas respostas, fiando-se nas respostas numéricas e nas justificativas dadas pelos demais respondentes na rodada anterior. Solicitavam-se novas previsões com justificativas. Esse processo costuma ser repetido por sucessivas rodadas até que a divergência seja reduzida a um nível satisfatório.

O uso de especialistas ainda é considerado um critério importante que confere credibilidade ao Delphi. A principal justificativa para reside na crença de que estes profissionais sejam formadores de opinião e tenham maior capacidade de avaliar as questões em foco (KAYO; SECURATO, 1997).

\section{Índice de Qualidade de Água}

Houve diversas tentativas de sistematizar, por meio de um índice, um conjunto de dados ou de parâmetros intervenientes em um determinado fenômeno, visando a torná-lo mais inteligível ao público em geral. Especificamente os índices de qualidade da água constituem meios para relatar informações coletadas dos sistemas de monitoramento por meio de um número, uma classe, uma descrição verbal ou uma cor.

Dentre os diversos indicadores citados com destaque variável na literatura, para proposição do IQAB há de se fazer distinção em relação ao Índice de Qualidade de Água (IQA) desenvolvido no início da década de 1970 e utilizado para avaliar os efeitos da poluição nos cursos d'água. Utilizou-se, então, a mencionada metodologia Delphi para estruturar a opinião de um grupo inicial de 142 especialistas de qualidade da água. Deste grupo, 77 mantiveram-se ao final da pesquisa, culminando com abstenção de $46 \%$.

Inicialmente, foi enviada aos 142 integrantes do painel uma lista composta por 35 parâmetros selecionados arbitrariamente para possível inclusão em um índice de qualidade da água. Cada participante deveria selecionar, para cada parâmetro, uma das opções: Incluir, Não Incluir ou Indeciso; era possível listar outros parâmetros que não estivessem inclusos nesta primeira lista. Cada parâmetro 
selecionado com o item 'Incluir' deveria ter um peso variando de 1 a 5. Um sumário dos resultados desta primeira rodada foi enviado aos participantes, junto com o segundo questionário, para que suas respostas fossem comparadas às respostas dadas pelo grupo e reavaliadas, sendo também solicitada uma lista dos 15 parâmetros mais importantes. Por fim, definiu-se uma lista composta por nove parâmetros e respectivos pesos integrantes do IQA, conforme denota a Figura 1.

Definidos os parâmetros integrantes do IQA e os respectivos pesos, no terceiro questionário coube ao painelista desenhar as curvas que, segundo seu julgamento, representassem a variação da qualidade da água produzida pelas várias possíveis medidas do parâmetro. As nove curvas utilizadas para o cálculo do IQA constituíram-se das curvas médias obtidas das respostas de todos os respondentes (BROWN et al, 1970).

A primeira formulação do IQA foi definida como o somatório do produto das notas pelos respectivos pesos de cada um dos nove parâmetros mostrados na Figura 1. Posteriormente, Landwehr e Deininger (1974) propuseram uma forma multiplicativa para o IQA devido fundamentalmente à possibilidade de um eventual valor muito baixo de um dos parâmetros se tornar menos evidente pela formulação anterior. $\mathrm{Na}$ forma multiplicativa, os pesos tornam-se potências dos pontos obtidos para cada parâmetro de qualidade de água.

A despeito do seu emprego em diversos países como indicador da saúde ambiental dos corpos d'água, o IQA, como qualquer índice, apresenta limitações. Evidencia-se uma nítida sobreposição de alguns parâmetros que fornecem informações semelhantes, tais como oxigênio dissolvido (OD) e demanda bioquímica de oxigênio (DBO), turbidez e sólidos totais, e, em muitas circunstâncias, coliformes termotolerantes e DBO.

Todavia, estas sobreposições não indicam a inaplicabilidade do IQA como indicador da tratabilidade das águas naturais. Uma vez que a maioria dos mananciais de abastecimento apresenta baixa $\mathrm{DBO}$, significativa concentração de OD à saturação - parâmetros que respondem em conjunto por $27 \%$ do índice - um índice que pudesse abranger outras características das águas naturais teria maior aplicabilidade. Similarmente, a maioria dos cursos d'água apresenta também baixa concentração de nitratos e fosfatos, pois tais parâmetros manifestam-se mais significativamente quando a captação é realizada a partir de reservatórios de acumulação com algum grau de eutrofização. Por fim, ainda no mesmo contexto, parâmetros como a cor verdadeira e a contagem de algas (e/ou cianobactérias) - ainda que subliminarmente contemplados no IQA - representam papel relevante no tratamento e seriam importantes balizadores para distinção da tratabilidade das águas naturais.

Diante do exposto, salvo alguns mananciais mais comprometidos, o IQA apresentaria resultados de mesma magnitude e interferiria pouco como instrumento de comparação das águas naturais em termos de maior ou menor dificuldade na potabilização.

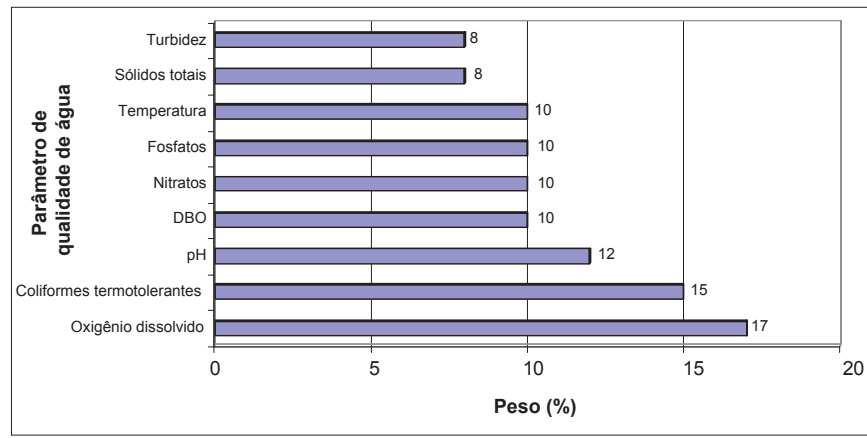

Figura 1 - Parâmetros de qualidade, e respectivos pesos, integrantes do IQA

\section{Metodologia}

A metodologia para elaboração do IQAB foi a mesma utilizada para o desenvolvimento do IQA e do mencionado IQETA. O IQAB é direcionado para a avaliação das características da água bruta afluente às estações convencionais de tratamento, contemplando águas de Classe 3, de acordo com a Resolução 357 (CONAMA, 2005).

\section{Pesquisa de opinião}

O painel foi composto por 24 especialistas em qualidade e tratamento de água com formação em nível superior em Engenharia Civil (20) e Ciências Biológicas (4) - a maioria detentora do título de Doutor (17) responsáveis por pesquisas, projetos e operação de estações de tratamento de água, abarcando universidades, companhias estaduais de saneamento e empresas de engenharia das regiões Sul e Sudeste (Tabela 1).

A definição final do tamanho do grupo delimitou-se em pesquisas similares nas quais se verificou elevada abstenção e longa duração com o emprego de grupos maiores. Adicionalmente, antes do envio do primeiro questionário, os painelistas foram questionados a respeito do interesse em participar da pesquisa, procedimento que resultou em menor abstenção. Na Tabela 2 apresenta-se o perfil profissional e geográfico dos especialistas.

A pesquisa foi desenvolvida em duas fases distintas, consoantes à metodologia Delphi. Inicialmente, elaborou-se uma lista com 21 parâmetros de caracterização das águas naturais, apresentada na Tabela 2 e incluída no primeiro questionário enviado aos painelistas.

Vale mencionar que, à exceção do carbono orgânico total (COT), quase a totalidade destes parâmetros é usualmente monitorada em parcela significativa das estações de médio e grande porte do País. Tal assertiva justifica a ausência de alguns parâmetros de qualidade e de tratabilidade de água relevantes, tais como contagem de partículas, carbono orgânico dissolvido, absorção UV-254, entre outros. Ambos os questionários foram enviados por meio de mensagem eletrônica devido à clara preferência manifestada pelos participantes em pesquisa anterior.

No primeiro questionário, apresentou-se uma introdução que explicitou todas as etapas da pesquisa, evidenciando o papel de cada 
Tabela 1 - Perfil profissional e geográfico dos 24 integrantes do painel de especialistas

\begin{tabular}{lccccc|} 
& \multicolumn{5}{c}{ Estados } \\
\cline { 2 - 6 } Perfil profissional & $\begin{array}{c}\text { Rio } \\
\text { Grande } \\
\text { do Sul }\end{array}$ & $\begin{array}{c}\text { Santa } \\
\text { Catarina }\end{array}$ & $\begin{array}{c}\text { Rio de } \\
\text { Janeiro }\end{array}$ & $\begin{array}{c}\text { São } \\
\text { Paulo }\end{array}$ & $\begin{array}{c}\text { Minas } \\
\text { Gerais }\end{array}$ \\
\hline Operador de estação & & & & & 2 \\
\hline $\begin{array}{l}\text { Projetista } \\
\text { Pesquisador }\end{array}$ & & 2 & 1 & 4 & 7 \\
\hline $\begin{array}{l}\text { Pesquisador/Projetista } \\
\text { Projetista/Operador }\end{array}$ & 1 & & & 2 & 1 \\
\hline Pesquisador/Operador & & & & & 1 \\
\hline
\end{tabular}

Tabela 2 - Lista das características das águas naturais incluídas no primeiro questionário enviado aos painelistas

\begin{tabular}{lllll} 
Turbidez & Cor verdadeira & E. coli & Dureza & $\begin{array}{l}\text { Coliformes ter- } \\
\text { motolerantes }\end{array}$ \\
\hline Algas & Cianobactérias & Alcalinidade & $\mathrm{pH}$ & $\begin{array}{l}\text { Coliformes } \\
\text { totais }\end{array}$ \\
$\begin{array}{lllll}\text { Sólidos } \\
\text { totais }\end{array}$ & Amônia & $\begin{array}{l}\text { Sólidos } \\
\text { dissolvidos }\end{array}$ & Temperatura & Cloretos \\
$\begin{array}{l}\text { Carbono Nitratos } \\
\text { orgânico } \\
\text { total }\end{array}$ & Fosfatos & Ferro & Manganês \\
\hline \begin{tabular}{l} 
Condutividade elétrica \\
\hline
\end{tabular} & & & \\
\hline
\end{tabular}

painelista, e uma segunda parte contendo as instruções para o seu correto preenchimento. Finalmente, a terceira parte constituía-se da mencionada lista das características das águas naturais apresentada na Tabela 2, para as quais o respondente deveria assinalar uma entre as três alternativas: Incluir, Não incluir e Indeciso. Após esta avaliação, caberia ao respondente atribuir uma nota até 100 - somente para as características anteriormente assinaladas como Incluir -, de acordo com sua influência na tratabilidade da água. Por fim, considerou-se a soma de todos os pontos atribuídos pelo respondente igual a 100, com vistas a facilitar a padronização da distribuição dos pesos.

Ao final desta primeira fase, elaborou-se o segundo questionário no qual se inseriu um relatório contemplando o sumário das respostas dos painelistas. Este relatório continha as médias e as medianas dos pesos conferidos às 21 características das águas naturais pelo grupo, a resposta do painelista e um resumo das observações e comentários dos respondentes. Neste segundo questionário, o respondente era convidado a reavaliar suas respostas à luz da opinião dos demais integrantes do painel e, seguindo premissa similar à adotada para a elaboração do IQA, a sugerir os oito parâmetros integrantes do IQAB. Finalmente, havia uma clara recomendação para que cada painelista priorizasse as características das águas superficiais mais comumente monitoradas na maioria das estações de tratamento brasileiras, objetivando conferir maior aplicabilidade ao Índice.

\section{Definição dos critérios de pontuação}

Após a definição dos parâmetros incluídos no IQAB e seus respectivos pesos, foram estabelecidos os critérios de pontuação a partir da influência de cada parâmetro na tratabilidade por meio da tecnologia convencional de potabilização. O desenvolvimento dos critérios de pontuação fundamentou-se na literatura técnica, no padrão de potabilidade estabelecido pela Portaria 518 e nas características comumente verificadas nas águas naturais afluentes às estações de tratamento brasileiras.

\section{Formulação do IQAB}

A formulação do índice objetivou agregar os parâmetros na combinação e simplificação para o cálculo final do IQAB. Com este intuito, utilizaram-se inicialmente o Produtório e o Somatório, conforme as equações 1 e 2 .

$\mathrm{IQAB}=\sum_{i=1}^{n} w_{i} q_{i}$

Equação 1

$\mathrm{IQAB}=\prod^{n} q_{i}^{\text {wit }}$

Equação 2

Nas quais:

$\mathrm{W}_{\mathrm{i}}$ peso atribuído a cada característica definido na pesquisa de opinião cuja somatória é igual a 100;

$\mathrm{q}_{\mathrm{i}:}$ pontuação atribuída a cada característica a partir dos critérios de pontuação;

i: característica da água natural incluída no índice;

n: número de características.

\section{Aplicação do IQAB}

Dados operacionais de cinco estações de tratamento referentes às características da água bruta foram empregados para avaliar a aplicabilidade do IQAB para ambas as formulações. O IQAB, nas formas de produtório e somatório, foi calculado por meio de planilhas feitas no programa Excel, utilizando-se a mediana dos valores para os parâmetros incluídos no índice, reportando-se três meses no período de estiagem e três meses no período chuvoso.

\section{Resultados e discussão}

\section{Respostas dos painelistas}

O primeiro questionário foi enviado aos 24 especialistas, sendo que 21 deles responderam a tempo de receberem o segundo questionário. Deste grupo, 18 mantiveram-se até o final da pesquisa, culminando com abstenção total de 25\%. Para ambas as etapas, definiu-se o tempo máximo de três meses para envio das respostas pelos painelistas.

Conforme já mencionado, no primeiro questionário facultou-se aos painelistas a possibilidade de sugerir a inserção de parâmetro(s) não incluído(s) na Tabela 2. Foram sugeridos como parâmetros microbiológicos: a contagem de esporos e de colifagos - para controle de protozoários e de Enterovírus, respectivamente -, em estações cujos mananciais apresentassem concentração E. coli superior a 1.000 
NMP/100 mL. Propôs-se, também, a inserção de outros metais, especialmente para cursos d'água receptores de despejos industriais, mesmo tratados. Nesta vertente, os metais deveriam ser quantificados em amostras de água digeridas e não-digeridas, para se ter uma ideia da necessidade ou não da pré-oxidação, pois em muitos casos determinaram-se concentrações de metais cinco a dez vezes maiores na amostra digerida em relação àquelas obtidas em amostra nãodigerida. Contudo, nenhum parâmetro foi sugerido por mais de dois painelistas e a lista inicial permaneceu inalterada.

Em relação aos resultados, algumas considerações se fazem relevantes. Apenas quatro participantes manifestaram indecisão quanto a alguns parâmetros. Os números máximo e mínimo de parâmetros incluídos foram 21 e 4, ambos definidos por apenas um participante, com o número médio variando entre 8 e 13 parâmetros. No primeiro questionário, os parâmetros 'Turbidez', 'cor verdadeira', 'E. coli' e 'cianobactérias' apresentaram maiores valores para a mediana, emergindo como os parâmetros de maior relevância para a formulação do IQAB.

Após o recebimento do segundo questionário, as respostas foram analisadas para a determinação dos pesos finais. Alguns pesos sofreram alterações, assim como ocorreram mudanças quanto às inclusões de alguns parâmetros por parte dos participantes. Na Figura 2 apresenta-se o percentual de inclusão de cada parâmetro de acordo com as respostas dos dois questionários.

Algumas constatações afloram a partir da análise dos percentuais de inclusão de cada parâmetro de qualidade de água apontados pelos painelistas. Como era de se esperar, a temperatura apresentou-se como característica pouco relevante, embora a coagulação de águas de baixa temperatura seja significativamente mais difícil, situação usual nos países temperados. Contudo, salvo algumas localidades específicas, as águas naturais nos países tropicais acabam por apresentar variação pouco significativa nas temperaturas médias, proporcionada pelo elevado calor específico deste fluido.

Uma segunda constatação reporta-se ao papel de destaque conferido ao parâmetro 'turbidez'. Como não é incomum estações de tratamento produzirem efluente filtrado com turbidez inferior a 0,5 uT, mesmo nos períodos chuvosos nos quais esta característica física na água bruta supera frequentemente $300 \mathrm{uT}$, esta supremacia parece retratar mais sua importância sanitária como indicador da remoção de cistos e oocistos de protozoários do que a dificuldade de remoção propriamente dita.

Ainda em relação aos resultados apresentados na Figura 2, evidencia-se a inaplicabilidade do IQA como indicador da tratabilidade das águas superficiais. Dos nove parâmetros que o integram (Figura 1), apenas $\mathrm{pH}$ e turbidez apresentaram percentual de inclusão superior a $60 \%$, de acordo com a opinião dos painelistas.

Conforme mencionado na metodologia, para favorecer a aplicabilidade do IQAB, optou-se por restringi-lo a oito parâmetros a serem definidos pelos painelistas no segundo questionário. Nesta escolha, os oito primeiros parâmetros listados na Figura 2 foram mantidos, ainda que com percentuais distintos, e novamente coube ao parâmetro 'turbidez' o maior percentual de inserção (100\%) entre os integrantes do IQAB, como mostra a Figura 3.

Finalmente, as respostas do segundo questionário permitiram estabelecer os pesos de cada um dos oito parâmetros integrantes do IQAB. Devido à dispersão dos pesos conferidos, decidiu-se empregar a mediana como medida de tendência central. Desta forma, os pesos finais dos parâmetros que compõem o IQAB (apresentados na Figura 4) foram assim definidos:

i) os pesos de cada parâmetro foram multiplicados pelo percentual de inclusão, mantendo-se os pesos dos parâmetros com percentual de $100 \%$ e reduzindo-se os demais;

ii) dividiu-se cada peso pelo total de pesos atribuídos pelo painelista de forma que o somatório fosse 100.

De acordo com a Figura 4, denota-se a coincidência do peso (12\%) atribuído ao parâmetro pH em relação ao IQA (Figura 1).

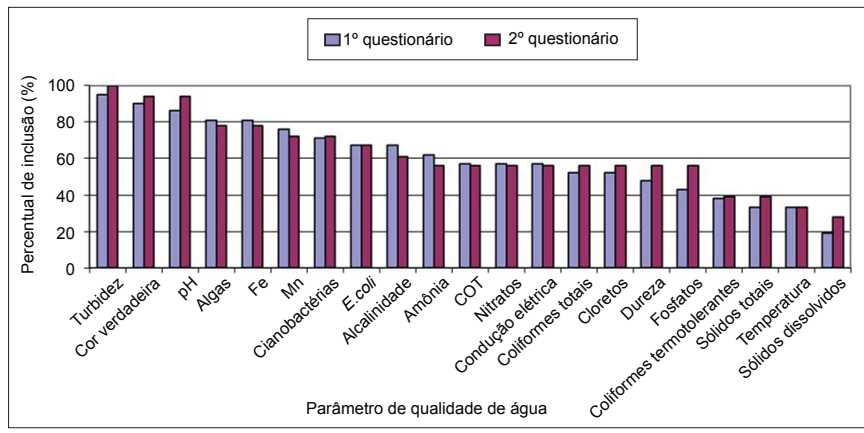

Figura 2 - Percentual de inclusão dos 21 parâmetros de qualidade de acordo com o painel

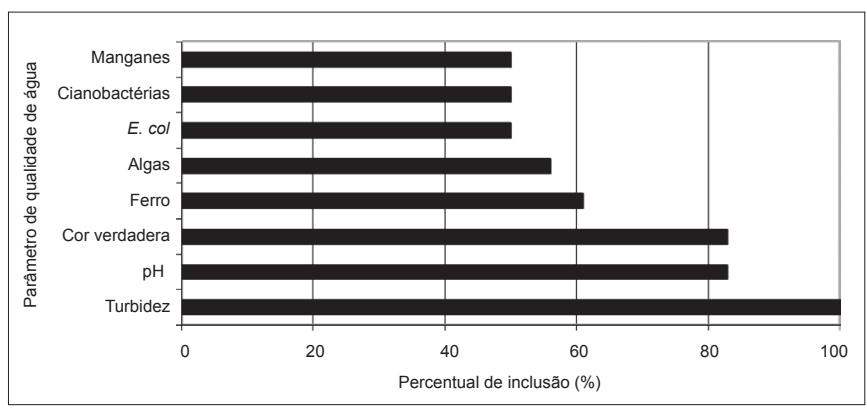

Figura 3 - Percentual de inclusão de cada parâmetro no IQAB

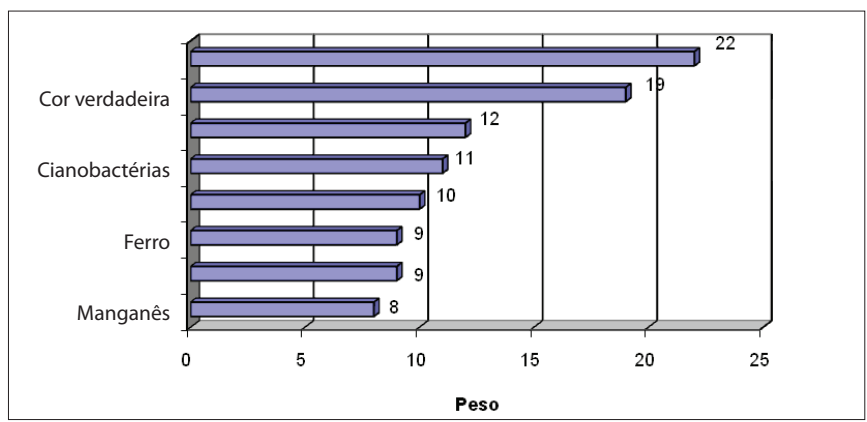

Figura 4 - Mediana dos pesos finais dos integrantes do IQAB 
Também a tendência do aumento da eutrofização dos mananciais - como consequência da poluição pontual e difusa -, e a própria dificuldade de remoção destes micro-organismos, manifestou-se no percentual de $21 \%$ do IQAB para conjunção dos parâmetros 'algas' e 'cianobactérias'. O IQAB também contemplou dois parâmetros de difícil remoção, 'cor verdadeira' e 'manganês', cuja simultaneidade - ainda que mais rara - pode conduzir à realização da coagulação em dois estágios. Tal situação consubstancia-se pelas distintas faixas de $\mathrm{pH}$ ótimo de coagulação, baixo para remoção da cor verdadeira e elevado para manganês. Esta situação não-usual no país é registradae na cidade finlandesa de Turku, em cuja estação (vazão média de $1,5 \mathrm{~m}^{3} / \mathrm{s}$ ) realiza-se dupla coagulação com sulfato férrico para valores de $\mathrm{pH}$ de coagulação da ordem de 5,0 e 10,5 (WAHLROOS, 1990).

Por fim, vale ressaltar que explicitamente não integram o padrão de potabilidade brasileiro os seguintes parâmetros: cor verdadeira, algas e cianobactérias. Em relação a esses parâmetros, as menções da Portaria 518 reportam-se aos limites para cor aparente (15 uH) e

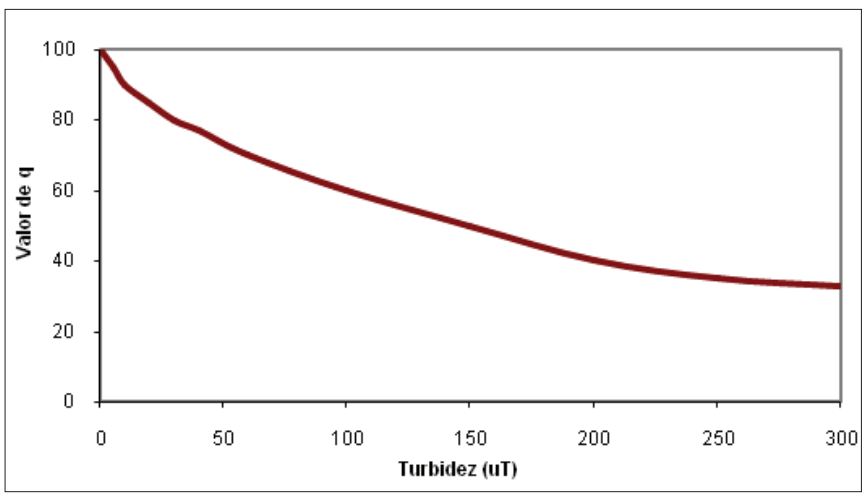

Figura 5 - Critério de pontuação para o parâmetro 'turbidez'

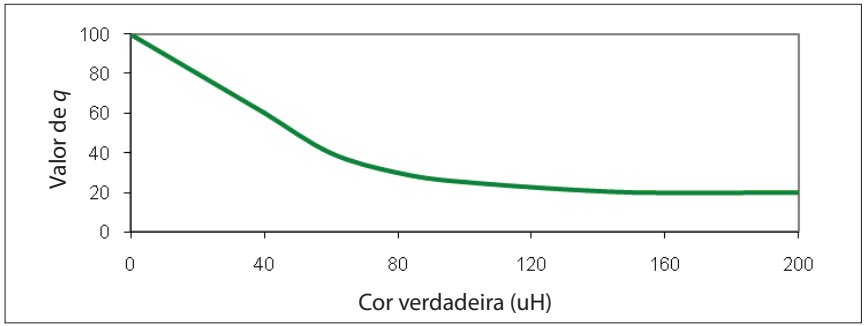

Figura 6 - Critério de pontuação para o parâmetro 'cor verdadeira'

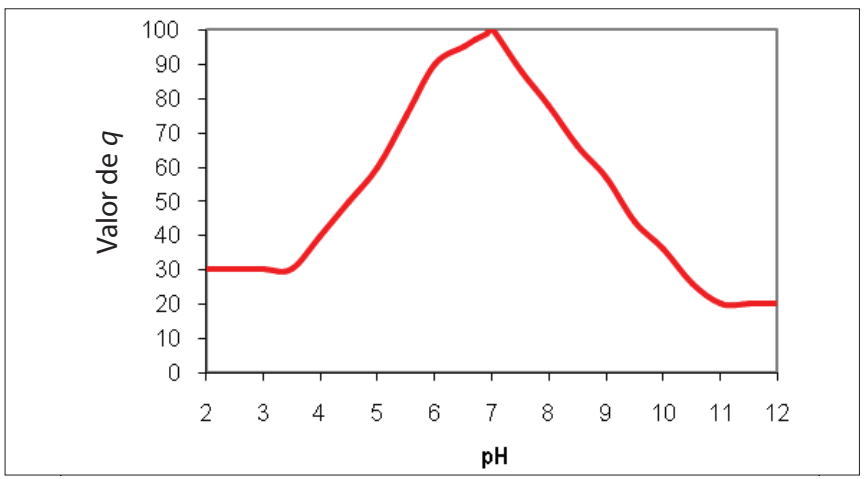

Figura 7 - Critério de pontuação para o parâmetro pH concentração de microcistina $(1,0 \mu \mathrm{g} / \mathrm{L})$ - recomendando-se inserção de saxitoxinas (3,0 $\mu \mathrm{g} / \mathrm{L}$ de equivalentes de STX/L) e cilindrospermopsinas $(15,0 \mu \mathrm{g} / \mathrm{L})$ - e ao monitoramento de cianobactérias. Tal constatação favorece a aplicabilidade do IQAB pela significativa maioria das concessionárias de abastecimento de água do país.

\section{Definição dos critérios de pontuação}

Conforme salientado, na elaboração do IQA, no terceiro questionário os painelistas foram instados a traçar curvas para cada parâmetro de qualidade. Para o desenvolvimento do IQAB, a perspectiva de que a pesquisa pudesse se prolongar demasiadamente culminou com a elaboração das curvas sem a participação dos painelistas. Desta forma, elaboraram-se as oito curvas norteadoras dos critérios de pontuação de cada parâmetro.

Observa-se que a pontuação dos parâmetros traduz o valor de $q$ na formulação do IQAB (equações 1 e 2), e o seu valor não pode ser nulo para nenhum parâmetro, pois anularia o índice na forma do produtório, inviabilizando-o como indicador da tratabilidade da água natural. Diferentemente das curvas utilizadas para o IQA, a elaboração das oito curvas aplicáveis ao IQAB contemplou o valor máximo (100) para todos os parâmetros.

A seguir são apresentadas as curvas referentes aos quatro parâmetros mais significativamente intervenientes na tratabilidade das águas naturais de acordo com a opinião dos painelistas, responsáveis em conjunto por $64 \%$ do IQAB.

Para o parâmetro 'turbidez', estabeleceu-se valor máximo de 300 uT, tornando o valor de $q$ assintótico para valores mais elevados, como mostra a Figura 5. Isso se deve à recorrente eficiência na remoção da turbidez quando a coagulação se realiza pelo mecanismo da varredura, mesmo para águas excessivamente turvas com turbidez superior a $1000 \mathrm{uT}$.

Na Figura 6, apresenta-se o critério de pontuação para cor verdadeira, para o qual se norteou pela variação usual deste parâmetro entre 0 e 200 uH, embora a Resolução 357 (CONAMA, 2005) reporte a cor verdadeira máxima de 75 uH para águas Classe 3.

A opção por valores mínimos de $q$ inferiores aos adotados para o parâmetro 'turbidez' (Figura 5) fiou-se na reconhecida maior dificuldade em remover a cor verdadeira, principalmente para águas de alcalinidade mais significativa, pois as melhores condições de coagulação comumente se manifestam para valores de $\mathrm{pH}$ mais baixos. Esta premissa orientou o conceito de coagulação melhorada estabelecido pela American Water Works Association, que preconiza remoção mínima de 20\% de COT por meio do progressivo aumento da dosagem de coagulante e manutenção do pH baixo para favorecer a desinfecção com o cloro.

Na Figura 7, exemplifica-se o critério de pontuação para pH. Nota-se que a pontuação do pH considera o emprego usual de alcalinizante e quase inusitado de ácido como auxiliares de coagulação nas estações de tratamento brasileiras. Neste contexto, o critério pautou- 
se por conferir valores maiores de $q$ para águas naturais com mais baixos valores de $\mathrm{pH}$ e vice-versa.

Ainda em relação à Figura 7, vale mencionar a distinção de a curva de pontuação do IQAB em comparação à estabelecida pelos painelistas inseridos na determinação do IQA. Esta última praticamente apresentase como uma curva típica de distribuição normal com a média no valor de $\mathrm{pH}$ 7,0, atingindo o valor nulo de $q$ para pH igual a 2,0 e 12,0.

Por fim, a elaboração da curva para pontuação referente ao parâmetro 'cianobactérias', apresentada na Figura 8, baseou-se nas recomendações da Portaria 518, na recorrente dificuldade de remoção e na perspectiva de geração de cianotoxinas. As primeiras referem-se à necessidade de monitoramento mensal para concentrações - ou densidades - superiores a 10.000 células/mL, e semanal para concentrações superiores a 20.000 células/mL. A mencionada dificuldade de remoção conduz, com alguma frequência e eficiência variável, à associação da pré-desinfecção ao dispendioso emprego do carvão ativado, comumente em pó, para adsorção das cianotoxinas dispersas na massa líquida após a lise celular.

Vale mencionar que, embora a Resolução 357 (CONAMA, 2005) estabeleça concentração máxima de algas em termos de clorofila-a (60 g/L para águas Classe 3), diversas concessionárias do País realizam o monitoramento a partir do número de indivíduos por $\mathrm{mL}$ ou mesmo UPA/mL (unidade padrão de área). Desta forma, para apenas um único parâmetro (algas) foram estabelecidos dois critérios distintos de pontuação - em função da concentração de clorofila-a e do número de indivíduos por $\mathrm{mL}$-, ainda que balizados nos mesmos conceitos da dificuldade de remoção.

\section{Aplicação do IQAB}

Após a definição dos pesos e dos critérios de pontuação para os oito parâmetros, determinaram-se os valores do IQAB, nas formas de produtório e somatório, à água bruta afluente a cinco estações convencionais de tratamento situadas no estado de Minas Gerais, com vazões médias de 65 a 5.800 L/s. Para tanto, utilizaram-se dados operacionais diários de 2008 abarcando as características da água bruta. Objetivando avaliar o impacto da sazonalidade, para uma das estações determinaram-se separadamente os valores do IQAB no período chuvoso - janeiro a março - e de estiagem - junho a agosto. Para as demais estações, determinou-se o IQAB apenas para o período chuvoso, prerrogativa fundamentada no princípio da mais difícil tratabilidade da maioria das águas naturais nessa época do ano.

Para o cálculo do IQAB, optou-se por empregar a mediana como medida de tendência central dos valores de cada parâmetro - alguns dos quais determinados com frequência horária. A primeira aplicação do IQAB se deu para água natural captada a partir de uma pequena barragem de nível. Devido à escassa atividade antrópica na bacia hidrográfica, a ausência de florações de algas e de cianobactérias tem justificado monitoramento apenas ocasional destes micro- organismos. As tabelas 3 e 4 apresentam as determinações do IQAB para os períodos chuvoso e de estiagem.

Da análise dos resultados expressos nas tabelas 3 e 4, depreendem-se algumas constatações. Como era de se esperar, o cálculo do IQAB pelo produtório torna-se mais suscetível a valores mais baixos de algum parâmetro, mesmo de menor peso, quando comparado ao somatório. Essa assertiva evidencia-se ainda mais claramente no período de estiagem, quando a usual melhora na tratabilidade das águas naturais é espelhada pela elevação mais significativa do IQAB na forma do produtório - da ordem de $70 \%$. Neste período, a distinção entre as

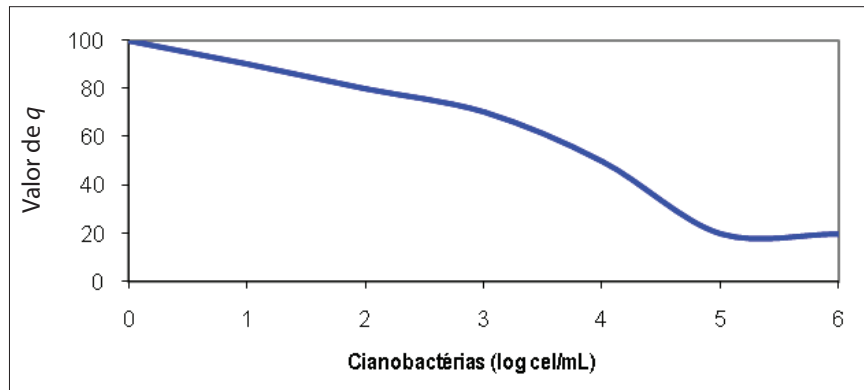

Figura 8 - Critério de pontuação para o parâmetro 'cianobactérias'

Tabela 3 - Exemplo de cálculo do IQAB para o período chuvoso

\begin{tabular}{|c|c|c|c|c|c|}
\hline $\begin{array}{l}\text { Parâmetro } \\
\text { (unidade) }\end{array}$ & Mediana & $\begin{array}{c}W \\
\text { (peso) }\end{array}$ & $\begin{array}{c}q \\
\text { (pontuação) }\end{array}$ & Somatório & Produtório \\
\hline Turbidez (UT) & 14,2 & 0,22 & 80 & 17,6 & 2,62 \\
\hline $\begin{array}{l}\text { Cor verdadeira } \\
(\mathrm{uH})\end{array}$ & 105 & 0,19 & 10 & 1,9 & 1,55 \\
\hline $\mathrm{pH}$ & 6,63 & 0,12 & 90 & 10,8 & 1,72 \\
\hline $\begin{array}{l}\text { Cianobactérias } \\
\text { (células } / \mathrm{mL} \text { ) }\end{array}$ & ND* & 0,11 & 100 & 11 & 1,66 \\
\hline $\begin{array}{l}\text { Algas } \\
\text { (células/mL) }\end{array}$ & $N D^{*}$ & 0,1 & 100 & 10 & 1,58 \\
\hline $\begin{array}{l}\text { E. coli } \\
\text { (NMP/100 mL) }\end{array}$ & 705 & 0,09 & 65 & 5,85 & 1,46 \\
\hline Ferro (mg/L) & 2,85 & 0,09 & 11 & 0,99 & 1,24 \\
\hline $\begin{array}{l}\text { Manganês } \\
\text { (mg/L) }\end{array}$ & 0,38 & 0,08 & 15 & 1,2 & 1,24 \\
\hline IQAB & & & & 59,34 & 41,12 \\
\hline
\end{tabular}

*não detectado

Tabela 4 - Exemplo de cálculo do IQAB para o período de estiagem

\begin{tabular}{|c|c|c|c|c|c|}
\hline $\begin{array}{l}\text { Parâmetro } \\
\text { (unidade) }\end{array}$ & Mediana & $\begin{array}{c}\text { W } \\
\text { (peso) }\end{array}$ & $\begin{array}{c}q \\
\text { (pontuação) }\end{array}$ & Somatório & Produtório \\
\hline Turbidez (UT) & 6,68 & 0,22 & 85 & 18,7 & 2,66 \\
\hline $\begin{array}{l}\text { Cor verdadeira } \\
\text { (uH) }\end{array}$ & 45 & 0,19 & 50 & 9,5 & 2,1 \\
\hline $\mathrm{pH}$ & 6,78 & 0,12 & 95 & 11,4 & 1,73 \\
\hline $\begin{array}{l}\text { Cianobactérias } \\
\text { (células } / \mathrm{mL} \text { ) }\end{array}$ & $N D^{*}$ & 0,11 & 100 & 11 & 1,66 \\
\hline $\begin{array}{l}\text { Algas } \\
\text { (células/mL) }\end{array}$ & $N D^{*}$ & 0,1 & 100 & 10 & 1,58 \\
\hline $\begin{array}{l}\text { E. coli } \\
\text { (NMP/100 mL) }\end{array}$ & 98 & 0,09 & 70 & 6,3 & 1,47 \\
\hline Ferro (mg/L) & 1,03 & 0,09 & 40 & 3,6 & 1,39 \\
\hline $\begin{array}{l}\text { Manganês } \\
\text { (mg/L) }\end{array}$ & 0,14 & 0,08 & 40 & 3,2 & 1,34 \\
\hline IQAB & & & & 73,7 & 69,4 \\
\hline
\end{tabular}

*Não houve análises destes parâmetros nos dois períodos amostrados. 
duas formulações torna-se menos evidente, confirmando a tendência dos valores do IQAB a aproximarem-se, e tornando a comparação entre distintas águas naturais menos acurada. Neste contexto, seguindo tendência de diversos órgãos ambientais em relação ao IQA, recomenda-se o emprego do IQAB, na forma do produtório, como ferramenta mais fidedigna para a avaliação da tratabilidade das águas naturais.

Por fim, a partir dos dados operacionais diários de janeiro a março de 2008, determinaram-se os valores do IQAB para água natural afluente a quatro estações de médio e grande porte. Na Tabela 5 , apresentam-se tais resultados.

A despeito da exiguidade da amostra, é interessante observar uma tendência dos valores do IQAB a reduzirem com o tempo de operação dos sistemas. Os dois sistemas com valores menores do IQAB, para ambas formulações, foram implantados há mais de 40 anos, tornando-os mais suscetíveis aos efeitos da ampliação do espaço urbano na alteração das características da água bruta. Corroboram esta afirmativa os esforços empreendidos pela concessionária na tratabilidade do afluente à Estação 3, que culminaram inclusive com a alteração do coagulante empregado após quase 20 anos de uso ininterrupto.

Uma segunda constatação, similar à reportada para os resultados da Tabela 4, remete à tendência de equalização dos valores do IQAB em ambas as formulações para águas naturais captadas em mananciais mais preservados, caso específico do manancial cuja água bruta aflui à Estação 1.

\section{Conclusões e recomendações}

i) O índice proposto abarca parâmetros comumente inseridos no padrão de potabilidade e na rotina operacional de monitoramento das águas superficiais utilizadas para fins de abastecimento. Esta constatação favorece seu emprego em escala real como ferramenta de avaliação da tratabilidade das águas superficiais e como instrumento de informação à sociedade da eficiência das ações de preservação dos mananciais realizadas pela concessionária.
Tabela 5 - Valores do IQAB e tipos de captação

\begin{tabular}{llccc}
$\begin{array}{l}\text { Estação de } \\
\text { tratamento }\end{array}$ & Captação & $\begin{array}{c}\text { Vazão } \\
\text { média (L/s) }\end{array}$ & $\begin{array}{c}\text { IQAB } \\
\text { somatório }\end{array}$ & $\begin{array}{c}\text { IQAB } \\
\text { produtório }\end{array}$ \\
\hline 1 & Direta & 380 & 92,19 & 91,9 \\
\hline 2 & Direta & 700 & 74,01 & 69,33 \\
\hline 3 & Direta & 5.800 & 55,94 & 42,57 \\
\hline 4 & $\begin{array}{l}\text { Reservatório de } \\
\text { acumulação }\end{array}$ & 3.400 & 77,24 & 74,39 \\
\hline
\end{tabular}

ii) O delineamento do IQAB, fiado na opinião de especialistas, confirmou a inaplicabilidade do IQA como indicador da tratabilidade das águas superficiais, pois apenas dois parâmetros ( $\mathrm{pH}$ e turbidez) integram ambos os indicadores. Ao conferir papel relevante às algas e às cianobactérias (21\% do total), a hierarquização proposta ressalta também o impacto da eutrofização dos corpos d'água quando se empregam a tecnologia convencional de tratamento e a decantação como etapa final da clarificação.

iii) A aplicação do IQAB a cinco águas naturais apontou a maior suscetibilidade da forma do produtório aos efeitos sazonais da qualidade da água, recomendando-se esta formulação como ferramenta de avaliação da tratabilidade do afluente às estações convencionais de tratamento. Esta distinção tende a ser menos evidente para águas de melhor qualidade.

\section{Agradecimentos}

Os autores agradecem aos painelistas pela participação, à Coordenação de Aperfeiçoamento de Pessoal de Nível Superior (Capes) pela concessão da bolsa de mestrado vinculada à pesquisa, ao Conselho Nacional de Desenvolvimento Científico e Tecnológico (CNPq) no contexto do Edital Universal 015/2007 e à Fundação de Amparo à Pesquisa do Estado de Minas Gerais (Fapemig) no recém-criado Programa Pesquisador Mineiro (Proc. TEC APQ 4754-6).

\section{Referências}

BRASIL. Ministério da Saúde. Portaria 518. Normas e padrão de potabilidade da água destinada ao consumo humano. Brasília, DF: Ministério da Saúde, mar. 2004.

BROWN, R.M. et al. A water quality index - do we dare? Water \& Sewage Works, Chicago, v. 117, n. 10, p. 339-343, Oct. 1970.

CONSELHO NACIONAL DO MEIO AMBIENTE (CONAMA). Resolução 357, de 25 de março de 2005.

KAYO, E.K.; SECURATO, J.R. Método Delphi: fundamentos, críticas e vieses, Caderno de Pesquisa em Administração, São Paulo, v. 1, n. 4, p. 51-61, abr. 1997.

LANDWEHR, J.M.; DEININGER, R.A. A comparison of several water quality indexes, Journal of Water Pollution Control Federation, v. 48, n. 5 , p. 954-958, May 1976.

LIBÂNIO, M.; LOPES, V.C. Assessing the feasibility of a water treatment plant quality index, Journal of Water Supply: Research and Technology AQUA, v. 58, n. 5, p. 354-362, Jun. 2009.

LINSTONE, H.A.; TUROFF, M. (Ed.). The Delphi Method: techniques and applications. Massachusetts, USA: Addison-Wesley Publishing Company, 1975.

WAHLROOS, G. Two-stage iron (III) coagulation as a method of improving the effectiveness of the water purification process. In: HAHN, H.H.; KLUTE, R. (Ed.). Chemical water and wastewater treatment, SpringerVerlag, Berlin, Germany: IWA Publishing, 1990 